Supporting Information of

\title{
Native Fluorescent Natural Deep Eutectic Solvents for green sensing applications: curcuminoids in Curcuma longa powder
}

\author{
Anabela S. Lorenzetti †, Ezequiel Vidalł, María F. Silva†, Claudia Domini ${ }^{*}$ and \\ Federico J.V. Gomez†*
}

†Instituto de Biología Agrícola de Mendoza (IBAM-CONICET) Facultad de Ciencias Agrarias Universidad Nacional de Cuyo Almirante Brown 500, Chacras de Coria, Mendoza, Argentina ‡INQUISUR, Departamento de Química, Universidad Nacional del Sur(UNS)-CONICET, Av. Alem 1253, 8000 Bahía Blanca, Argentina.

Number of figures: 2 (Figures S1-S2)

Number of tables: 6 (Tables S1-S6)

Number of pages: 8 (S1-S8)

${ }^{*}$ Corresponding authors

E-mail address: claudia.domini@uns.edu.ar (CD), fedeg33@gmail.com (FJVG) 

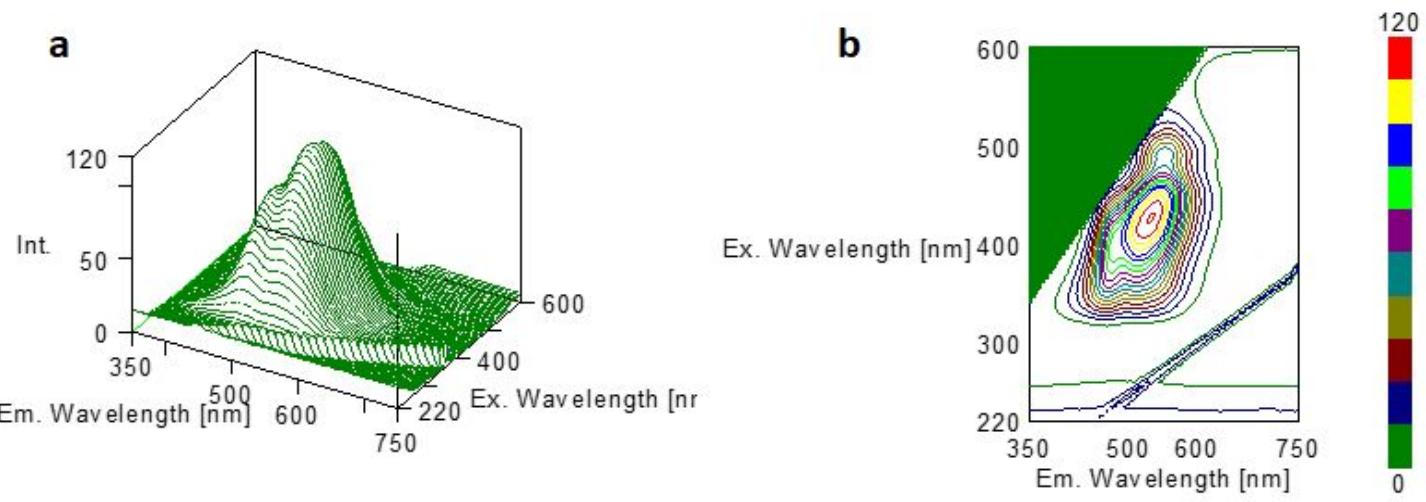

Figure S1: (a) 3D spectrum and (b) contour 3D spectrum of $\mathrm{FCH}$

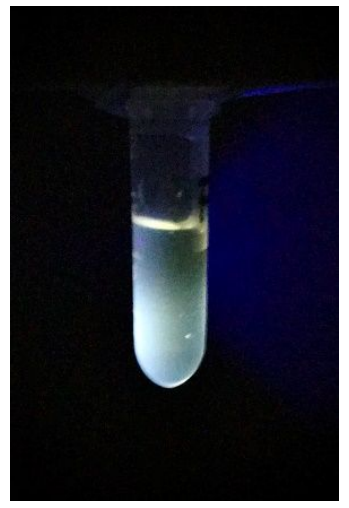

Figure S2: Fluorescence of FCH illuminated with a Blacklight 365nm UV flashlight

Table S1: Hydrogen bond donor and acceptor count, rotatable bond count and topological polar surface area ${ }^{1}$ of tested components for NADES preparation

\begin{tabular}{|c|c|c|c|c|}
\hline Component & $\begin{array}{c}\text { Hydrogen Bond } \\
\text { Donor Count }\end{array}$ & $\begin{array}{c}\text { Hydrogen Bond } \\
\text { Acceptor Count }\end{array}$ & $\begin{array}{c}\text { Rotatable Bond } \\
\text { Count }\end{array}$ & $\begin{array}{c}\text { Topological } \\
\text { Polar Surface } \\
\text { Area }\left(\AA^{2}\right)\end{array}$ \\
\hline Fructose & 5 & 6 & 1 & 110 \\
\hline Glucose & 5 & 6 & 1 & 110 \\
\hline Sucrose & 8 & 11 & 5 & 190 \\
\hline Citric acid & 4 & 7 & 5 & 132 \\
\hline Choline chloride & 1 & 2 & 2 & 20.2 \\
\hline Lactic acid & 2 & 3 & 1 & 57.5 \\
\hline Glycerol & 3 & 3 & 2 & 60.7 \\
\hline Water & 1 & 1 & 0 & 1 \\
\hline
\end{tabular}


Table S2: Analytical Greenness report sheet for Industrial Crops and Products 140 (2019) $111620^{2}$

\section{Analytical Greenness report sheet} for Industrial Crops and Products 140 (2019) 111620² $28 / 12 / 202011: 42: 23$

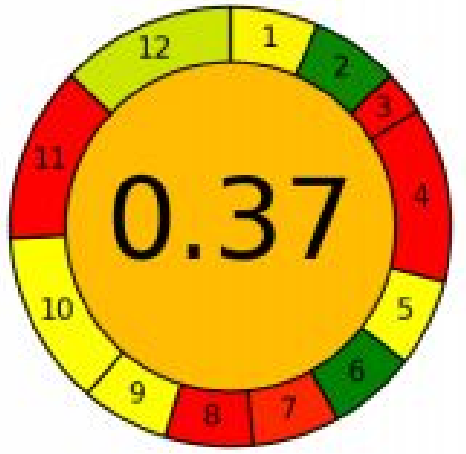

Criteria Score Weight \begin{tabular}{|l|l|l|l|}
\hline 1. Direct analytical techniques should be applied to avoid sample & 0.48 & 2 \\
\hline
\end{tabular} treatment. 2. Minimal sample size and minimal number of samples are goals.

3. If possible, measurements should be performed in situ.

4. Integration of analytical processes and operations saves energy and reduces the use of reagents.

\begin{tabular}{|l|l|l}
\hline 5. Automated and miniaturized methods should be selected. & 0.5 & 2 \\
\hline
\end{tabular}

\begin{tabular}{|l|l|l}
\hline 6. Derivatization should be avoided. & 1.0 & 2 \\
\hline
\end{tabular}

\begin{tabular}{|l|c|c|}
\hline $\begin{array}{l}\text { 7. Generation of a large volume of analytical waste should be avoided, and } \\
\text { proper management of analytical waste should be provided. }\end{array}$ & 0.08 & 2 \\
\hline
\end{tabular}

8. Multi-analyte or multi-parameter methods are preferred versus methods using one analyte at a time.

\begin{tabular}{|l|l|l}
\hline 9. The use of energy should be minimized. & 0.5 & 2 \\
\hline
\end{tabular}

10. Reagents obtained from renewable sources should be preferred.

11. Toxic reagents should be eliminated or replaced. 
Table S3: Analytical Greenness report sheet for Ultrasonics-Sonochemistry 70 (2021) $105267^{3}$

Analytical Greenness report sheet for Ultrasonics - Sonochemistry 70 (2021) 105267s

$28 / 12 / 202012: 16: 34$

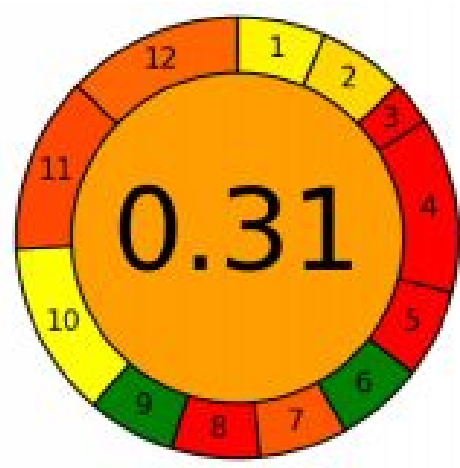

Criteria

Score Weight

\begin{tabular}{|l|l|l|l|}
\hline 1. Direct analytical techniques should be applied to avoid sample & 0.48 & 2
\end{tabular}
treatment

3. If possible, measurements should be performed in situ.

4. Integration of analytical processes and operations saves energy and reduces the use of reagents.

\begin{tabular}{|l|l|l|l|l|}
\hline 5. Automated and miniaturized methods should be selected. & 0.0 & 2
\end{tabular}

\begin{tabular}{|l|l|l|}
\hline 6. Derivatization should be avoided. & 1.0 & 2 \\
\hline
\end{tabular}

\begin{tabular}{|l|c|c|}
\hline $\begin{array}{l}\text { 7. Generation of a large volume of analytical waste should be avoided, and } \\
\text { proper management of analytical waste should be provided. }\end{array}$ & 0.17 & 2 \\
\hline
\end{tabular}

8. Multi-analyte or multi-parameter methods are preferred versus methods using one analyte at a time.

\begin{tabular}{|l|l|l|}
\hline 9. The use of energy should be minimized. & 1.0 & 2 \\
\hline
\end{tabular}

\begin{tabular}{|l|l|l|}
\hline 10. Reagents obtained from renewable sources should be preferred. & 0.5 & 4 \\
\hline
\end{tabular}

\begin{tabular}{|l|l|l|}
\hline 11. Toxic reagents should be eliminated or replaced. & 0.14 & 4
\end{tabular}

12. Operator's safety should be increased. 
Table S4: Analytical Greenness report sheet for Ultrasonics Sonochemistry 38 (2017) $437-445^{4}$

Analytical Greenness report sheet for Ultrasonics Sonochemistry 38 (2017) 437-4454

28/12/2020 13:30:03

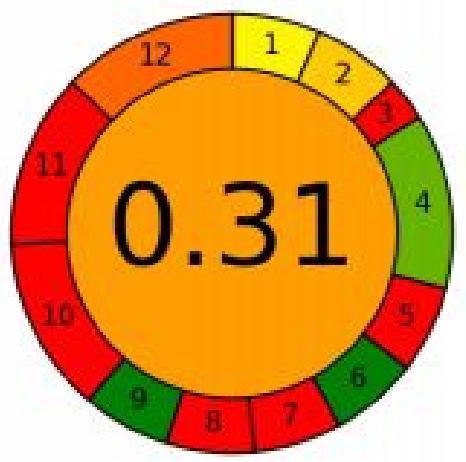

Criteria

Score

Weight

\begin{tabular}{l}
\begin{tabular}{|l|c|c|}
\hline 1. Direct analytical techniques should be applied to avoid sample & 0.48 & 2 \\
treatment.
\end{tabular} \\
\hline
\end{tabular}

2. Minimal sample size and minimal number of samples are goals.

3. If possible, measurements should be performed in situ.

4. Integration of analytical processes and operations saves energy and reduces the use of reagents.

5. Automated and miniaturized methods should be selected.

6. Derivatization should be avoided.

7. Generation of a large volume of analytical waste should be avoided, and proper management of analytical waste should be provided.

8. Multi-analyte or multi-parameter methods are preferred versus methods using one analyte at a time.

9. The use of energy should be minimized.

10. Reagents obtained from renewable sources should be preferred.

11. Toxic reagents should be eliminated or replaced. 
Table S5: Analytical Greenness report sheet for Journal of Food Science and Technology 47 (2010) 300-3045

Analytical Greenness report sheet for Journal of Food Science and Technology 47(3) (2010) $300-304^{5}$

28/12/2020 13:44:11

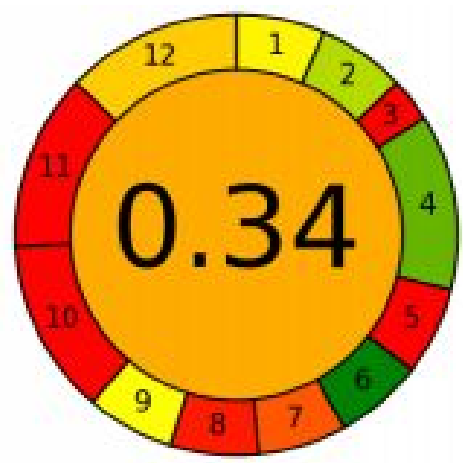

Criteria

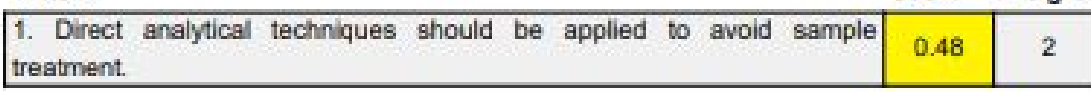

\begin{tabular}{|l|l|l|}
\hline 2. Minimal sample size and minimal number of samples are goals. & 0.65 & 2 \\
\hline
\end{tabular}

\begin{tabular}{|l|l|l|}
\hline 3. If possible, measurements should be performed in situ. & 0.0 & 1 \\
\hline
\end{tabular}

\begin{tabular}{|l|l|l|}
\hline $\begin{array}{l}\text { 4. Integration of analytical processes and operations saves energy and } \\
\text { reduces the use of reagents. }\end{array}$ & 0.8 & 4 \\
\hline
\end{tabular}

\begin{tabular}{|l|l|l|}
\hline 5. Automated and miniaturized methods should be selected. & 0.0 & 2 \\
\hline
\end{tabular}

5. Automated and miniaturized methods should be selected.

6. Derivatization should be avoided.

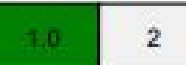

\begin{tabular}{|l|c|c|}
\hline $\begin{array}{l}\text { 7. Generation of a large volume of analytical waste should be avoided, and } \\
\text { proper management of analytical waste should be provided. }\end{array}$ & 0.17 & 2 \\
\hline
\end{tabular}
proper management of analytical waste should be provided.

8. Multi-analyte or multi-parameter methods are preferred versus methods using one analyte at a time.

9. The use of energy should be minimized.

10. Reagents obtained from renewable sources should be preferred.

11. Toxic reagents should be eliminated or replaced. 
Table S6: Analytical Greenness report sheet for our work Analytical Greenness report sheet for this work

28/12/2020 12:40:01

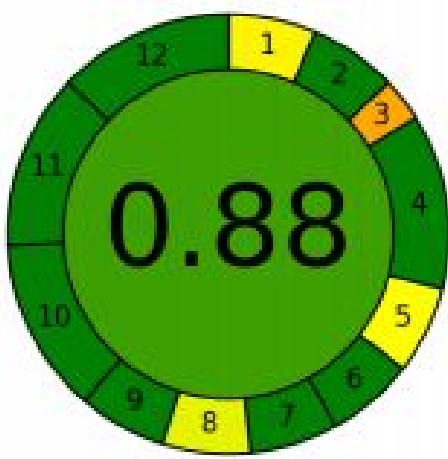

Criteria

Score Weight

1. Direct analytical techniques should be applied to avoid sample treatment.

2. Minimal sample size and minimal number of samples are goals.

\begin{tabular}{|l|c|c|}
\hline 3. If possible, measurements should be performed in situ. & 0.33 & 1 \\
\hline
\end{tabular}

4. Integration of analytical processes and operations saves energy and reduces the use of reagents.

\begin{tabular}{|l|l|l|}
\hline 5. Automated and miniaturized methods should be selected. & 0.5 & 2 \\
\hline
\end{tabular}

\begin{tabular}{|l|l|l|}
\hline 6. Derivatization should be avoided. & 1.0 & 2 \\
\hline
\end{tabular}

\begin{tabular}{l|l|l}
\hline $\begin{array}{l}\text { 7. Generation of a large volume of analytical waste should be avoided, and } \\
\text { proper management of analytical waste should be provided. }\end{array}$ & 1.0 & 2
\end{tabular}

\begin{tabular}{|l|c|c|}
\hline $\begin{array}{l}\text { 8. Multi-analyte or multi-parameter methods are preferred versus methods } \\
\text { using one analyte at a time. }\end{array}$ & 0.55 & 2 \\
\hline
\end{tabular}

\begin{tabular}{|l|l|l}
\hline 9. The use of energy should be minimized. & 1.0 & 2 \\
\hline
\end{tabular}

10. Reagents obtained from renewable sources should be preferred.

11. Toxic reagents should be eliminated or replaced. 


\section{References}

(1) https://pubchem.ncbi.nlm.nih.gov/

(2) Liu, Y.; Li, J.; Fu, R.; Zhang, L.; Wang, D.; Wang, S. Enhanced Extraction of Natural Pigments from Curcuma Longa L. Using Natural Deep Eutectic Solvents. Ind. Crops Prod. 2019, 140 (May), 111620. https://doi.org/10.1016/j.indcrop.2019.111620.

(3) Patil, S. S.; Pathak, A.; Rathod, V. K. Optimization and Kinetic Study of Ultrasound Assisted Deep Eutectic Solvent Based Extraction: A Greener Route for Extraction of Curcuminoids from Curcuma Longa. Ultrason. Sonochem. 2021, 70 (July 2020), 105267. https://doi.org/10.1016/j.ultsonch.2020.105267.

(4) Shirsath, S. R.; Sable, S. S.; Gaikwad, S. G.; Sonawane, S. H.; Saini, D. R.; Gogate, P. R. Intensification of Extraction of Curcumin from Curcuma Amada Using Ultrasound Assisted Approach: Effect of Different Operating Parameters. Ultrason. Sonochem. 2017, 38 (March), 437-445. https://doi.org/10.1016/j.ultsonch.2017.03.040.

(5) Sogi, D. S.; Sharma, S.; Oberoi, D. P. S.; Wani, I. A. Effect of Extraction Parameters on Curcumin Yield from Turmeric. J. Food Sci. Technol. 2010, 47 (3), 300-304. https://doi.org/10.1007/s13197-010-0047-8. 